\title{
Posttraumatic Stress Disorder in a Swiss offender population
}

Frank Urbaniok, férôme Endrass, Thomas Noll, Stefan Vetter, Astrid Rossegger

Psychiatric-Psychological Service, Zurich Department of Justice, Switzerland

\section{Summary}

Questions under study: Various studies have repeatedly shown an increased prevalence for Posttraumatic Stress Disorder (PTSD) in delinquents when compared with the general population. Lifetime prevalence varies between $33 \%$ and $36 \%$, and point prevalence between $17 \%$ and $21 \%$.

The aim of this study was to examine whether these findings are applicable to offenders detained in Switzerland.

Methods: The sample consisted of 86 offenders. In order to control for over-reporting of traumatic life events three sub-samples (remand, sentenced/inpatient and sentenced/outpatient) administered by the Office of Corrections of the Canton of Zurich were examined. PTSD was diagnosed using the Posttraumatic Diagnostic Scale (PDS), a self-rating instrument for diagnosing PTSD according to the Diagnostic and Statistical Manual of Mental Disorders, Version IV (DSM-IV).
Results: Point prevalence of PTSD was conservatively estimated at $27 \%$. The three sub-samples did not differ in the prevalence of PTSD when adjusted for potential demographic differences. Seventy-five percent of the subjects had experienced at least one traumatic event that matched the criteria for a traumatic event according to the DSMIV. The Median number of traumatising life events according to the PDS was four in the examined sample.

Conclusions: In this sample of male prisoners in Switzerland the prevalence of current PTSD was comparable to other international studies. The limitations and implications of these findings were discussed. lence

\section{Introduction}

Numerous studies focusing on the psychopathology and biography of offenders have concluded that delinquents have an increased prevalence for psychological disorders compared to the general population [1-4] and are more frequently exposed to traumatic life events [5-8].

Dutton and Hart [5] investigated a Canadian prison sample and found that $31 \%$ of the inmates were victims of physical abuse in childhood and adolescence, $11 \%$ suffered from sexual abuse, and $13 \%$ said they had been neglected or had witnessed abusive behaviour between their parents. Lake [6] reported that $11 \%$ of prison inmates were victims of a sexual assault. Furthermore they found that nearly three-quarters $(74 \%)$ of the study sample had at one time been physically assaulted by a stranger, with $41 \%$ of them needing medical treatment as a consequence.

Concerning the general victimisation rate, Weeks and Widom [7] reported a considerably higher prevalence of victimisation in a New York state prison sample of $68 \%$. Sixteen percent re- ported having been neglected, $14 \%$ reported sexual abuse and 34-58\% reported physical abuse (depending on the examination instrument). A similar result was reported by Gibson et al. [8], with $68 \%$ of the inmates of a US penitentiary previously exposed to a traumatising situation.

As it's a well-known finding that sexual abuse and rape are especially high risk factors for developing Posttraumatic Stress Disorder (PTSD) [9, 10], the elevated rate of PTSD in delinquents compared to the general population is not surprising $[1,3,4,11,12]$. Representative statistics of the prevalence of traumatic experiences and PTSD in the general US population showed a lifetime prevalence of PTSD between $8 \%$ and $10 \%[9,10]$. This figure is considerably lower for European countries: a recent study with a representative random sample of non-institutionalised inhabitants from six European countries (Belgium, France, Germany, Italy, the Netherlands, and Spain) showed a lifetime prevalence of $1.9 \%$ (males: $0.9 \%$, and females: $2.9 \%$ ) [13]. 
In US penitentiaries, the lifetime prevalence of PTSD in male detainees is 33\% [11]. These results were the basis for a study by Gibson et al. [8], who corroborated the lifetime prevalence of $33 \%$ for developing PTSD. At the time of the survey, 21\% met PTSD criteria and $68 \%$ had experienced a traumatic event. Those who met PTSD criteria at one point in their life named having witnessed a violent assault, rape or physical violence to be the most disturbing events experienced, followed by being raped and experiencing other forms of physical violence.

One of the few studies investigating European offenders examined 54 delinquents detained in German forensic psychiatric institutions (according to paragraphs 63 and 64 of the German Penal Code) and found a lifetime prevalence of $36 \%$ for
PTSD and a point prevalence of $17 \%$ [12]. Lifetime prevalence for PTSD was $56 \%$ in delinquents who had had at least one traumatic experience. The most frequent traumatic experience was victimisation during childhood (sexual or physical abuse), accounting for $35 \%$, followed by self-committed offences.

As stated in the introduction, various analyses repeatedly showed that offenders reveal an increasing prevalence for PTSD and associated symptoms when compared with the general population. This paper asks whether these findings are applicable to offenders detained in Switzerland. We hypothesised that the prevalence of PTSD among prisoners in Swiss prisons is comparable to the prevalence rates reported in US investigations.

\section{Method}

\section{Sample}

The study sample was composed of 86 male offenders administered between November 2003 and April 2004 by the Office of Corrections of the Canton of Zurich, Switzerland. Recently it has been shown that the selection of the sample is of particular importance in offender studies and that different predictors of recidivism are found for sanction and verdict samples [14].

The present study was intended to analyse several groups of offenders of different legal status, namely: remand prisoners (group 1: remand), convicted offenders receiving therapy within a correctional facility (group 2: sentenced/inpatient), and convicted offenders receiving therapy on an outpatient basis (group 3: sentenced/outpatient).

A further reason for selecting three different groups was that offenders might be motivated to different degrees to report stressful life experiences, which could lead to over-reporting or even under-reporting of symptoms [15]. It is hypothesised that this strategic reporting behaviour would be different for the three different offender groups, depending on whether the offender is at a stage in the legal process at which he might hope that the reporting of traumatic experiences would have an impact on his sentence or probational status. Accordingly, if a difference in reporting were to be found, it is argued that most over-reporting would be found in the remand group, as the likelihood of reporting having an influence on their situation (ie the impending verdict) would be the highest.

A basic knowledge of the German language was a prerequisite for participating in the study. Women were excluded from the study because it is known that men and women differ with regard to PTSD prevalence $[9,10,16]$.

For the group of remand prisoners, all male inmates with at least basic knowledge of German in Zurich's largest remand prison («Bezirksgefängnis Zürich») were asked to participate in the study. In 2001, the number of foreigners among inmates amounted to $80 \%$, which amounted to 122 of 152 prisoners. During the study-period, 28 inmates were sufficiently fluent in German and were asked to participate: 3 refused and 25 agreed. This group had not yet been convicted or assigned a clear legal status (remand group $\mathrm{n}=25$ ).

A second and third group consisted of convicted offenders undergoing treatment. All therapists of the Office of Corrections of the Canton of Zurich were obliged to ask their clients whether they wanted to participate, provided that the therapeutic process allowed it and they were sufficiently fluent in German. At the time of the investigation there were 102 offenders in treatment guided by the Psychiatric-Psychological Service of the Office of Corrections, which is the only service that is entitled to provide psychotherapy in the penitentiary and in the prisons of the Canton of Zurich. Of these 102 offenders 72 agreed to participate. Exclusion criteria were psychotic disorders, suicidal ideations, and severe intramural violent infractions that led to solitary confinement, which decreased the sample further to 61 subjects. Half of these offenders were detained in Switzerland's largest state penitentiary, the Zurich cantonal state penitentiary "Pöschwies" (sentenced/inpatient, $\mathrm{n}=31$ ) and were undergoing court-ordered therapy. The other half were nondetained delinquents (sentenced/outpatient, $n=30$ ). This group consisted of convicted delinquents undergoing therapy - by court-order or voluntarily - as post-sentence treatment, while on parole or during a prison sentence suspended in favour of therapy.

\section{Diagnostic Assessment}

PTSD was diagnosed with the help of the PDS (Posttraumatic Diagnostic Scale). The PDS [17] is a self-rating scale with which the degree of trauma can be quantified and PTSD can be diagnosed. The PDS measures PTSD symptomatology experienced by the client 1 month prior to the assessment and is similar to the operationalisation of PTSD in the DSM-IV. Consequently the PDS is a conservative measure of PTSD since DSM-IV criteria are more narrowly understood than ICD-10 criteria [18].

The DSM-IV requires operationalised event factors and the specific emotional reactions of a person upon them. According to the DSM-IV, PTSD exists if a person shows any symptoms of the three clusters of re-experiencing, avoidance behaviour and over-excitation after a traumatic event (one which corresponds with the definition of trauma), provided these symptoms have occurred for at least one month and led to impairment or suffering [19]. According to the DSM-IV, an event is classified as traumatic if a person has experienced or witnessed a lifethreatening event or an event which endangers the phys- 
ical integrity of oneself or a third person. In addition, a person needs to have shown intense reactions of fear, helplessness or horror after the event (DSM-IV).

Despite the problem of over-reporting of traumatic incidences [15], the PDS proved to be a valid instrument for assessing PTSD [20] and has been used in several studies in German-speaking countries [21,22].

\section{Interviewing procedures}

All interviews were held by a clinical psychologist of the Office of Corrections of the Canton of Zurich, familiar with PTSD and offender treatment. First, all subjects were clearly informed that participation in the study was voluntary and that no information would be passed on to the correctional services. Furthermore, to provide the subjects with a maximum feeling of security, the study was conducted strictly anonymously to reduce both the possibility that subjects would consciously give false statements in the hope of improving their situation as well as avoid- ing some disadvantage. In addition to the questionnaires, only age, sex and professional training were registered. Other data, such as name, nationality or crime criteria (such as type of offence) was not registered.

Even though the PDS is a self-rating instrument, the different items of the instrument were discussed and the questionnaire filled out with the psychologist. Administrating the PDS in a clinical interview helps maintaining the internal validity of the instrument [23]. Offenders who reported multiple traumatic experiences were asked to indicate the most traumatic one (= index event, the event on which PTSD diagnosis is based on).

\section{Statistical analysis}

Multivariable logistic regression with covariate adjustment for potential socio-demographic differences was used for an estimation and comparison of PTSD prevalence in the three sub-samples. The models were estimated using STATA SE 9.0.

\section{Results}

\section{Socio-demographic characteristics of the study sample}

The delinquents were 38.7 years old on average, the individual age ranged between 18 and 62 . Seventy-seven subjects agreed to provide information on their professional training. Thirty-two percent $(\mathrm{n}=25)$ did not complete their professional training or were unskilled workers, 39\% $(\mathrm{n}=30)$ were blue-collar and 29\% ( $\mathrm{n}=22)$ whitecollar workers. In table 1 information on vocational training and age of the offender population of Switzerland's largest state penitentiary ("Pöschwies") is provided as a comparison to the offender sample of the present study.

\section{Prevalence of traumatic life events}

More than half of the delinquents examined had experienced a serious accident $(63 \%, \mathrm{n}=54)$, $35 \%(n=30)$ of the subjects had experienced a violent assault by a family member, and $53 \%(n=46)$ a violent assault by a stranger. Ten percent $(\mathrm{n}=9)$ had experienced sexual assault by a family member

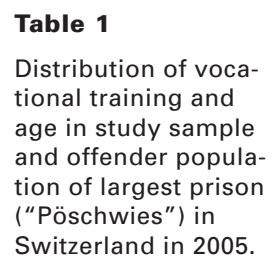

\begin{tabular}{lll} 
& \multicolumn{2}{l}{ Population } \\
\cline { 2 - 3 } Study (\%) & Prison (\%) \\
\hline Training & 34.8 & 36.1 \\
\hline Blue collar & 25.6 & 21.2 \\
\hline White collar & 29.1 & 32.3 \\
\hline No training & 10.5 & 10.4 \\
\hline No information & 2.5 & 1.3 \\
\hline Age (in years) & 14.8 & 22.4 \\
\hline Up to 19 & 35.8 & 34.8 \\
\hline $20-29$ & 33.3 & 26.9 \\
\hline $30-39$ & 12.4 & 11.1 \\
\hline $40-49$ & 1.2 & 3.5 \\
\hline $50-59$ &
\end{tabular}

and $16 \%(n=14)$ by a stranger; $14 \%(n=12)$ stated they had experienced torture. $93 \%$ of the study sample had a history of incarceration, which was usually reported as the most traumatic experience, i.e. the index event.

Almost all the subjects examined (99\%) had experienced at least one potentially traumatic event according to the PDS list. The median of stressful experiences according to the PDS amounted to 4 events for the total sample with an interquartile range of 2 to 6 events.

\section{Prevalence of PTSD}

In $75 \%$ of the subjects, the most stressful event at the time of evaluation met the DSM-IV criteria for an event that may trigger PTSD. The diagnostic criteria for PTSD were met in one-third of the cases $(34 \%, n=29)$.

Especially in detained offenders there is a danger of overestimating PTSD prevalence by attributing symptoms of adjustment disorder or reaction to imprisonment to PTSD. Therefore the index event "imprisonment" was disregarded for diagnosis in order to obtain a more conservative estimate of PTSD prevalence. If "imprisonment" was excluded $63 \%$ of subjects experienced an index event according to DSM-IV. Due to this change, the prevalence of PTSD diagnosis was reduced to $27 \%(\mathrm{n}=23)$.

In the three sub-samples the following prevalences of conservative estimation of PTSD (namely without the index event "imprisonment") were found: the subjects of the remand group showed the largest proportion of PTSD (32\%), while in the inpatient treatment group this proportion was at its lowest (25\%) and a good fourth of the offenders in outpatient treatment met PTSD criteria (26\%).

When adjusted for age and vocational training, the differences of PTSD prevalence (conser- 
Table 2

Amount and type of traumatic life events.

Table 3

Traumatic life events and prevalence of PTSD diagnosis.

\begin{tabular}{|c|c|c|c|c|c|}
\hline & $\begin{array}{l}\text { Remand } \\
(n=25)\end{array}$ & $\begin{array}{l}\text { Inpatient } \\
(n=31)\end{array}$ & $\begin{array}{l}\text { Outpatient } \\
(\mathbf{n}=30)\end{array}$ & $\begin{array}{l}\text { Total sample } \\
(\mathrm{n}=86)\end{array}$ & $\begin{array}{l}\text { Index } \\
\text { event }\end{array}$ \\
\hline Median amount of traumatising life events & $M d=4(2-6)$ & $M d=5(3-6)$ & $M d=3(2-4)$ & $M d=4(2-6)$ & \\
\hline Serious accident & $72 \%$ & $68 \%$ & $50 \%$ & $63 \%$ & $10 \%$ \\
\hline Natural disaster & $24 \%$ & $26 \%$ & $20 \%$ & $23 \%$ & $0 \%$ \\
\hline Violent assault by family member & $44 \%$ & $45 \%$ & $17 \%$ & $35 \%$ & $4 \%$ \\
\hline Violent assault by stranger & $40 \%$ & $74 \%$ & $43 \%$ & $53 \%$ & $13 \%$ \\
\hline Sexual assault by family member & $4 \%$ & $13 \%$ & $13 \%$ & $10 \%$ & $6 \%$ \\
\hline Sexual assault by stranger & $12 \%$ & $13 \%$ & $23 \%$ & $16 \%$ & $4 \%$ \\
\hline Residence in disaster and conflict area & $32 \%$ & $7 \%$ & $7 \%$ & $14 \%$ & $2 \%$ \\
\hline Intercourse before age 18 with 5 y older person & $20 \%$ & $55 \%$ & $40 \%$ & $40 \%$ & $1 \%$ \\
\hline Imprisonment & $100 \%$ & $100 \%$ & $80 \%$ & $93 \%$ & $26 \%$ \\
\hline Torture & $16 \%$ & $19 \%$ & $7 \%$ & $14 \%$ & $1 \%$ \\
\hline Life-threatening disease & $24 \%$ & $29 \%$ & $27 \%$ & $27 \%$ & $7 \%$ \\
\hline Miscellaneous & $40 \%$ & $39 \%$ & $33 \%$ & $37 \%$ & $26 \%$ \\
\hline
\end{tabular}

Note: Index event = event on which PTSD-diagnosis is based

\begin{tabular}{|c|c|c|c|c|}
\hline & $\begin{array}{l}\text { Remand } \\
(\mathrm{n}=25)\end{array}$ & $\begin{array}{l}\text { Inpatient } \\
(\mathrm{n}=31)\end{array}$ & $\begin{array}{l}\text { Outpatient } \\
(\mathrm{n}=30)\end{array}$ & $\begin{array}{l}\text { Total sample } \\
(\mathrm{n}=86)\end{array}$ \\
\hline Experience of at least one traumatic life event accord. DSM-IV & $79 \%$ & $83 \%$ & $63 \%$ & $75 \%$ \\
\hline PTSD diagnosis & $44 \%$ & $26 \%$ & $35 \%$ & $34 \%$ \\
\hline $\begin{array}{l}\text { Experience of at least one traumatic life event accord. DSM-IV } \\
\text { excl. imprisonment }\end{array}$ & $58 \%$ & $80 \%$ & $50 \%$ & $63 \%$ \\
\hline Conservative PTSD diagnosis & $32 \%$ & $25 \%$ & $26 \%$ & $27 \%$ \\
\hline
\end{tabular}

Table 4

Multivariable logistic regression: the odds of conservative PTSD diagnosis with covariate adjustment for age, vocational training and judicial stage.

\begin{tabular}{|c|c|c|c|}
\hline & OR & $\mathbf{P}$ & $95 \% \mathrm{CI}$ \\
\hline \multicolumn{4}{|l|}{ Training } \\
\hline none & 1 & & Reference \\
\hline Blue collar profession & 0.38 & 0.11 & $0.115-1.241$ \\
\hline White collar profession & 0.20 & 0.04 & $0.046-0.897$ \\
\hline Age per 10 years & 1.03 & 0.33 & $0.972-1.088$ \\
\hline \multicolumn{4}{|l|}{ Judicial stage } \\
\hline Sentenced/inpatient & 1 & & Reference \\
\hline Sentenced/outpatient & 0.77 & 0.70 & $0.198-2.980$ \\
\hline Remand & 1.36 & 0.67 & $0.334-5.533$ \\
\hline
\end{tabular}

\section{Discussion}

In summary, it can be stated that various international studies support the emergence of an increased prevalence for psychological disorders in delinquents $[1,3,4,24]$. The prevalence of PTSD among offenders has less frequently and only recently been examined. However, these studies too found an increased prevalence of PTSD in delinquents $[8,11,12]$. It has been the aim of this analysis to check whether these results also apply to Switzerland.

Nearly two-thirds of the subjects had experienced at least one traumatic event (excluding imprisonment), which met the criteria for a traumatic event according to the DSM-IV.

At the time of the analysis, one third of the participants fulfilled the diagnostic criteria for PTSD vative estimation) in the three sub-samples were not significant, even though the offender group with the lowest prevalence served as the reference cell in the dummy coded variable. There was, however, a negative association between professional background and PTSD prevalence. The prevalence of PTSD was lower among the offenders with a white-collar professional background than among unskilled workers. according to the DSM-IV. The diagnostic criteria of PTSD and "adjustment disorder" overlap to some degree. In order to obtain a robust estimate of the PTSD prevalence it may be sensible to adjust the diagnostic algorithm by omitting "imprisonment" as the most strenuous experience. However, this procedure only seems conclusive in subjects who stated "imprisonment" (meaning their current imprisonment) as the most stressful event at the time of the evaluation (index-incident). If no PTSD is assumed for this group, the prevalence of PTSD drops from $34 \%$ to $27 \%$. Based on the present data, it cannot be stated conclusively whether a minor part of the prevalence found may be better explained by the diagnosis of an adjustment disorder. Thus we assume a point 
PTSD-prevalence of $27 \%$ in the delinquents examined.

Like other international studies, we can assume that even though there are no representative results for the general population of Switzerland, the prevalence among offenders is considerably elevated. Furthermore the prevalence is slightly higher than in other international studies among offenders, where point prevalence was recorded between $17 \%$ [12] and 21\% [8].

It may be assumed that the present analysis overestimated the PTSD prevalence. Causes may be a false interpretation of the surveys by the people tested, or deliberately false answers. An argument against the assumption that the prevalence was overestimated due to misunderstanding of the questions is that the questionnaires were filled out together with a psychologist during a clinical interview [23].

It may be possible that the subjects gave incorrect answers deliberately, expecting advantages by reporting traumatogenic experiences. However, the data were collected anonymously, and additional characteristics (such as offences and police records etc.) were not taken into account, to make it impossible for the recorded information to be subsequently attributed to the subjects, and to reduce the likelihood of such a distortion. In doing so, the processes were arranged so that the strict anonymity of the data collection was made transparent and comprehensible to the participants. If strategic predication behaviour is assumed despite this process, it would seem chiefly plausible in the remand participants, who may have hoped to take advantage of it for an impending court case.

Such an interest would hardly be justified in prison inmates and even less so in delinquents who have already served their sentence. It might therefore be assumed that the three groups of delinquents examined (remand, sentenced/inpatient, and sentenced/outpatient) differ with regard to the prevalence of PTSD, if strategic predication behaviour has an influence on the prevalence of PTSD recorded. Since there was no significant difference between the three groups neither in regard to median number of reported stressful life events nor in regard to prevalence of PTSD, it seems unlikely that any predication behaviour had been strategically motivated. However, the association between traumatic life events (or PTSD) and offending is less clear. There are different approaches to explaining the frequent occurrence of delinquent behaviour after victimisation experiences. Depending on the approach, psychological, social (i.e. learned experience) or biological factors are considered the main factors in a circle of violence.

Bandura [25] showed that role-models play a crucial role in learning various social (and aggressive) behaviour. Bandura's social learning model [25] can be applied to delinquent behaviour after victimization experiences. As victims, future delinquents learn that violence poses a legitimate in- strument for establishing oneself. The conclusion that numerous primary families of delinquents display psychiatric disorders and delinquent behaviour may be an indication for a genetic predisposition for criminal behaviour [26, 27]. Adshead [28] points out that the high rate of traumatic events and abuse detainees experienced during childhood may indirectly increase the chance of criminal actions later on, particularly in men in the case of violent delinquency. This assumption is supported by Rivera and Widom [29]: in a prospective study, they compared the later delinquency of 908 individuals who had been sexually abused or neglected before the age of twelve with a matched random study of 667 individuals who had not been abused or neglected. Those abused or neglected during childhood showed a higher risk for violent delinquency and began their criminal career at an earlier stage. In the Dutton and Hart [5] study, those inmates who were abused had a three-fold increased risk of violent offences, and sexually abused inmates a five-fold risk of sexual offences. A longitudinal study [29] investigating a sample of 908 abused children supported this finding: in abused children, the risk of offending was considerably elevated and offending occurred earlier. In a German sample of 54 inmates of a forensic institution, $9 \%$ of the patients reported that their own offence triggered the PTSD. So far, it has been unclear how to explain the significantly higher prevalence of PTSD in delinquents. On the one hand, it may be possible that persons suffering from PTSD (or stressful experiences) are more likely to commit an offence. On the other, delinquents may be more likely to develop PTSD after an offence. The results of this analysis cannot provide an explanation for this.

Overall, we can assume that $27 \%$ of the examined group of delinquents showed PTSD at the time of the examination. Even though the prevalence rate is robust across sub-populations in Switzerland and comparable to international results, the question whether this finding is representative for the general offender population in Switzerland has to be addressed in future investigations.

Further analyses will focus particularly on the frequency and type of potentially traumatogenic experiences and the beginning of PTSD in delinquents convicted in Switzerland; the role of their own offence in developing PTSD should receive particular attention.
Correspondence:
Astrid Rossegger
Psychiatrisch-Psychologischer Dienst
Fustizvollzug Kanton Zürich
Feldstrasse 42
CH-8090 Zürich
Switzerland
E-Mail: astrid.rossegger@ji.zh.ch 


\section{References}

1 Teplin LA, Abram KM, McClelland GM. Prevalence of psychiatric disorders among incarcerated women: Pretrial jail detainees. Arch Gen Psychiatry. 1996;53:505-12.

2 Bland RC, Newman SC, Thompson AH, Dyck RJ. Psychiatric Disorders in the Population and in Prisoners. Int J Law Psychiatry. 1998;21:273-9.

3 Fazel S, Danesh J. Serious mental disorder in 23000 prisoners: a systematic review of 62 surveys. Lancet. 2001;359:545-50.

4 Höhner G. Verweildauer, Diagnosen und Delikte der \$63Forensik-Patienten der Rheinischen Landeskliniken. Monatsschrift für Kriminologie. 1993;76:83-90.

5 Dutton DG, Hart SD. Evidence for long-term, specific effects of childhood abuse and neglect on criminal behavior in men. International Journal of Offender Therapy and Comparative Criminology. 1994;36:129-37.

6 Lake E. Offenders experiences of violence: A comparison of male and female inmates as victims. Deviant Behavior. 1995; 16:269-90.

7 Weeks R, Widom CS. Self-Reports of Early Childhood Victimization among Incarcerated Adult Male Felons. J Interpers Violence. 1994;13:346-61.

8 Gibson LE, Holt JC, Fonacaro KM, Tang TS, Powell TA, Turbitt EL. An examination of antecendent trauma and psychiatric comorbidity among male inmates with PTSD. J Trauma Stress. 1999;12:473-84.

9 Breslau N, C. KR, Chilcoat HD, Schultz LR, Davis GC, Andreski P. Trauma and posttraumatic stress disorder in the community: The 1996 Detroit Area Survey of Trauma. Arch Gen Psychiatry. 1998;55:626-32.

10 Kessler RC, Sonnega A, Bromet E, Hughes M. Posttraumatic stress disorder in the National Comorbidity Survey. Arch Gen Psychiatry. 1995;52:1048-60.

11 Powell TA, Holt JC, Fonacaro KM. The prevalence of mental illness among inmates in a rural state. Law Human Behav. 1997;21:427-38.

12 Spitzer C, Dudeck M, Liss H, Orlob S, Gillner M, Freyberger HJ. Posttraumativ tress Disorder in Forensic Patients. J Forensic Pychiatry. 2001;12:63-77.

13 Alonso J, Angermeyer MC, Bernert S, Bruffaerts R, Brugha TS Bryson H, et al. Prevalence of mental disorders in Europe: Results from the European Study of the epidemiology of mental disorders (ESEMeD) project. Acta Psychiatr Scand. 2004;109: 21-7.

14 Urbaniok F, Endrass J, Rossegger A, Noll T, Gallo WT, Angst J. The prediction of criminal recidivism: The implication of sampling in prognostic models. Eur Arch Psychiatry Clin Neurosci accepted for publication.
15 McNally RJ. Debunking Myths About Trauma and Memory. The Canadian Journal of Psychiatry. 2005;50:13

16 Perkonigg A, Kessler RC, Storz S, Wittchen HU. Traumatic events and post-traumatic stress disorder in the community: Prevalence, risk factors and comorbidity. Acta Psychiatr Scand. 2000;101:46-59.

17 Foa EB, Riggs DS, Gershuny BS. Arousal, numbing, and intrusion: symptom structure of PTSD following assault. Am J Psych. 1995;152:116-20.

18 Ehlers A. Posttraumatische Belastungsstörung. Göttingen: Hogrefe; 1999.

19 Sass H. Diagnostisches und statistisches Manual psychischer Störungen DSM-IV: Übersetzt nach der 4. Auflage des Diagnostic and Statistical Manual of Mental Disorders der American Psychiatric Association. Göttingen: Hogrefe; 1998.

20 Griffin MG. Comparison of the Posttraumatic Stress Disorder Scale Versus the Clinician-Administered Posttraumatic Stress Disorder Scale in Domestic Violence Survivors. J Trauma Stress. 2004;17

21 Vogel M, Spitzer C, Barnow S, Freyberger HJ, Grabe HJ. The Role of Trauma and PTSD-Related Symptoms for Dissociation and Psychopathological Distress in Inpatients with Schizophrenia. Psychopathology. 2006;39:236-42.

22 Brauchle G. Persistent Dissociation as Predictor of Posttraumatic Stress Disorder in Psychosocial Disaster Workers. Psychother Psychosom Med Psychol 2006.

23 Howgego IM, Owen C, Meldrum L, Yellowlees P, Dark F, Parslow R. Posttraumatic stress disorder: an exploratory study examining rates of trauma and PTSD and its effect on client outcomes in community mental health. BMC Psychiatry. 2005; $5: 21$.

24 Fädrich S, Pfäfflin F. Zur Prävalenz von Persönlichkeitsstörungen bei Strafgefangenen. Recht und Psychiatrie. 2000;18: 95-104.

25 Bandura A. Aggression. Eine sozial-lerntheoretische Analyse. Stuttgart: Klett-Cotta; 1979.

26 Mednick SA, Gabrielli WF, Hutchings B. Genetic influences in criminal convictions: Evidence from an adoption cohort. Science. 1984;224:891-4.

27 Schulsinger F. Psychopathy: Heredity and enviroment. Int J Mental health. 1972;1:190-206.

28 Adshead G. Damage: Trauma and violence in a sample of woman referred to a forensic service. Behav Sci Law. 1994;12: $235-49$.

29 Rivera B, Widom CS. Childhood victimization and violent offending. Violence Vic. 1990;5:19-35. 